OPEN ACCESS

Edited by:

Song Guo Zheng, MD, PhD,

Penn State Milton S. Hershey

Medical Center

United States

Reviewed by:

Deborah J. Fowell,

University of Rochester,

United States

Chunhua Song,

Pennsylvania State University,

United States

*Correspondence:

Stephen M. Anderton

steve.anderton@ed.ac.uk

Specialty section:

This article was submitted to Immunological Tolerance

and Regulation,

a section of the journal

Frontiers in Immunology

Received: 13 September 2017

Accepted: 30 January 2018

Published: 26 February 2018

Citation:

Mair I, Zandee SEJ, Toor IS, Saul L,

McPherson RC, Leech MD,

Smyth DJ, O'Connor RA,

Henderson NC and Anderton SM (2018) A Context-Dependent Role

for $\alpha v$ Integrins in Regulatory

$T$ Cell Accumulation at Sites

of Inflammation.

Front. Immunol. 9:264.

doi: 10.3389/fimmu.2018.00264

\section{A Context-Dependent Role for $\alpha v$ Integrins in Regulatory T Cell Accumulation at Sites of Inflammation}

\author{
Iris Mair, Stephanie E. J. Zandee, Iqbal S. Toor, Louise Saul, Rhoanne C. McPherson, \\ Melanie D. Leech, Danielle J. Smyth, Richard A. O’Connor, Neil C. Henderson \\ and Stephen M. Anderton*
}

MRC Centre for Inflammation Research, Centre for Multiple Sclerosis Research, BHF Centre for Cardiovascular Science, and Centre for Immunity Infection and Evolution, University of Edinburgh, Edinburgh, United Kingdom

Several inflammatory diseases including multiple sclerosis and inflammatory bowel disease have been associated with dysfunctional and/or reduced numbers of Foxp3 ${ }^{+}$regulatory $T$ cells (Treg). While numerous mechanisms of action have been discovered by which Treg can exert their function, disease-specific Treg requirements remain largely unknown. We found that the integrin $\alpha v$, which can pair with several $\beta$ subunits including $\beta 8$, is highly upregulated in Treg at sites of inflammation. Using mice that lacked $\alpha \vee$ expression or $\beta 8$ expression specifically in Treg, we demonstrate that there was no deficit in Treg accumulation in the central nervous system during experimental autoimmune encephalomyelitis and no difference in the resolution of disease compared to control mice. In contrast, during a curative T cell transfer model of colitis, Treg lacking all $\alpha \mathrm{v}$ integrins were found at reduced proportions and numbers in the inflamed gut. This led to a quantitative impairment in the ability of $\alpha \mathrm{v}$-deficient Treg to reverse disease when Treg numbers in the inflamed colon were below a threshold. Increase of the number of curative Treg injected was able to rescue this phenotype, indicating that $\alpha v$ integrins were not required for the immunosuppressive function of Treg per se. In accordance with this, $\alpha v$ deficiency did not impact on the capacity of Treg to suppress proliferation of naive conventional $T$ cells in vitro as well as in vivo. These observations demonstrate that despite the general upregulation of $\alpha v$ integrins in Treg at sites of inflammation, they are relevant for adequate Treg accumulation only in specific disease settings. The understanding of disease-specific mechanisms of action by Treg has clear implications for Treg-targeted therapies.

\section{Keywords: integrin $\alpha v$, Foxp3, regulatory T cell, experimental autoimmune encephalomyelitis, colitis, autoimmune} disease, inflammation, resolution of inflammation

\section{INTRODUCTION}

Regulatory T cells (Treg) are a major target in the search for novel therapies for immune-mediated diseases-both through pharmacological manipulation and cell-based therapies $(1,2)$. They display a plethora of mechanisms by which they can mediate immune suppression, including cytolysis, modulation of antigen presenting cells, metabolic disruption, and secretion of inhibitory cytokines

\footnotetext{
Abbreviations: CNS, central nervous system; DC, dendritic cell; EAE, experimental autoimmune encephalomyelitis; iLN, inguinal lymph node; LP, lamina propria; mLN, mesenteric lymph node; pMOG, 35-55 peptide of mouse myelin oligodendrocyte glycoprotein; pOVA, ovalbumin peptide 323-339; Tn, naive CD4+ T cells; Treg, regulatory T cells; WT, wild-type.
} 
such as TGF- $\beta$, IL-10, and IL-35 (3). Treg are responsible for the inhibition of inadequate $\mathrm{T}$ cell activation in secondary lymphoid organs, but also migrate to inflamed sites to control ongoing inflammation. In order to optimally target Treg, it is important to understand how Treg are recruited to sites of inflammation and which suppressive mechanisms they deploy, which may well be dictated in organ- or disease-specific manners (4-9).

Most circulating Treg display a phenotype resembling that of naive conventional $\mathrm{T}$ cells and have been coined central Treg (10). Central Treg are thought to be important in preventing the activation of autoreactive $\mathrm{T}$ cells by antigen-presenting cells in secondary lymphoid organs (11). However, a small fraction of circulating Treg displays an activated phenotype and shows enhanced migration through non-lymphoid tissue. The homeostatic requirements of these so-called effector Treg are poorly understood, but at least some populations appear to be IL-2 independent $(10,12,13)$. The surface expression of chemokine receptors $(10,14-16)$, as well as integrins such as $\alpha \mathrm{E}(17,18)$, $\alpha \mathrm{L}$ (19), and $\beta 7$ (5) has been shown to define Treg migration to specific sites.

Integrins, consisting of an $\alpha$ and a $\beta$ subunit, are important players in cell adhesive functions and motility, but are also involved in intracellular signaling modulating cell survival, proliferation and differentiation (20). $\alpha \mathrm{v}$ integrins $(\alpha \mathrm{v} \beta 1, \alpha \mathrm{v} \beta 3, \alpha \mathrm{v} \beta 5, \alpha \mathrm{v} \beta 6$, $\alpha v \beta 8$ ) all recognize the RGD tripeptide sequence found in several components of the extracellular matrix as well as latent TGF- $\beta$ $(21,22)$ and have recently been associated with important functions in several immune cells. $\alpha v \beta 1$ and $\alpha v \beta 3$ have been linked to interstitial migration of $\mathrm{CD}^{+}$effector T cells (23) and $\alpha v \beta 8$ has been shown to be the key driver for TGF- $\beta$ activation by CD103 ${ }^{+}$ dendritic cells (DCs) and thereby immune homeostasis in the gut (24-26). Recently, the integrin $\alpha v \beta 8$ has also been implicated in activation of latent TGF- $\beta$ by Treg $(27,28)$. However, their common binding site would suggest that redundancy is highly likely between $\alpha v$ integrins.

On this point, the contribution of $\alpha \mathrm{v}$ integrins other than $\alpha v \beta 8$ to Treg function in homeostatic or inflammatory settings is unknown. Using conditional knockout mice lacking either all $\alpha \mathrm{v}$ integrins or only the integrin $\alpha \mathrm{v} \beta 8$, we investigated the role of $\alpha v$ integrins in Treg function under inflammatory conditions. We found that $\alpha v$ integrins (but not specifically $\alpha v \beta 8$ ) were required for efficient Treg accumulation in the inflamed intestine and resolution of inflammation, but had no role in Treg activity during central nervous system (CNS) inflammation.

\section{MATERIALS AND METHODS}

\section{Mice, Antigens, and Tissue Culture Medium}

All mice used were on the I- $\mathrm{A}^{\mathrm{b}}$ background. Rag1 ${ }^{-1-}$ mice and congenically identifiable (CD45.1) OT-II transgenic mice with a TCR reactive toward ovalbumin peptide 323-339 (pOVA) (29) were maintained at the University of Edinburgh. Foxp3 ${ }^{\text {tm4(YFP/cre)Ayr }}$ mice (30) were kindly provided by Dr. A. Rudensky. Itgav $v^{\mathbb{f} / f l}$ mice (25) were crossed with Foxp $3^{\operatorname{tm} 4(\mathrm{YFP} / \mathrm{cre}) \text { Ayr }}$ mice to generate conditional Foxp3- $\alpha \mathrm{v}^{-/-}$mice. Similarly, $\operatorname{Itg} b 8^{\mathrm{f} / \mathrm{fl}}$ mice (31) were crossed with Foxp $3^{\text {tm4(YFP/cre)Ayr }}$ mice to generate conditional Foxp3- $\beta 8^{-1-}$ mice. Conditional knockout mice were screened by PCR assessing the presence of the floxed $\alpha \mathrm{v}$ or $\beta 8$ gene, respectively, and the presence of the CRE gene. These lines expressed YFP under control of the Foxp3 promoter. All mice were bred under specific pathogen-free conditions at the University of Edinburgh. All experiments were approved by the University of Edinburgh Ethical Review Committee and were performed in accordance with UK legislation. The pOVA peptide and the 35-55 peptide of mouse myelin oligodendrocyte glycoprotein (pMOG) were obtained from Cambridge Research Biochemicals (Teesside, UK). Tissue culture medium (RPMI 1640 medium) was supplemented with $2 \mathrm{mM}$ L-glutamine, $100 \mathrm{U} / \mathrm{ml}$ penicillin, $100 \mu \mathrm{g} / \mathrm{ml}$ streptomycin, and $50 \mu \mathrm{M} 2-\mathrm{ME}$ (all from Gibco, Paisley, UK) plus 10\% FCS (Labtech, East Sussex, UK).

\section{Cell Purification and Culture}

$\mathrm{CD}^{+} \mathrm{T}$ cells were purified by magnetic cell sorting (Miltenyi Biotec, Germany) prior to surface staining and sorting by FACS. CD4 ${ }^{+}{\text {YFP CD } 62 L^{\text {hi }}}^{-}$naive T cells from Foxp $3^{\text {tm4(YFP/cre)Ayr }}$ mice were used as responder $\mathrm{T}$ cells for in vitro suppression assays as well as disease-inducing cells in the $\mathrm{T}$ cell transfer colitis models. $\mathrm{CD}^{+}{ }^{+} \mathrm{YFP}^{-} \mathrm{CD} 6 \mathrm{~L}^{\mathrm{hi}}$ naive $\mathrm{T}$ cells from Foxp3 $3^{\mathrm{tm} 4(\mathrm{YFP} / \mathrm{cre}) \text { Ayr }}$, Foxp3$\alpha \mathrm{v}^{-/-}$or Foxp3- $\beta 8^{-/-}$mice were also used as starting populations for induced Treg (iTreg) generation as previously described (32). $\mathrm{CD}^{+} \mathrm{YFP}^{+}$nTreg were isolated from Foxp3 $3^{\mathrm{tm} 4(\mathrm{YFP} / \mathrm{cre}) \mathrm{Ayr}}$, Foxp3$\alpha \mathrm{v}^{-/-}$or Foxp $3-\beta 8^{-/-}$mice and tested for their suppressive capacity in in vitro suppression assays or in T cell transfer colitis models. In vitro stimulation was provided by anti-CD3e (clone $145.2 \mathrm{C} 11$; eBioscience, Hatfield, UK) plus anti-CD28 (clone 37.51; eBioscience) at $2 \mu \mathrm{g} / \mathrm{ml}$ each. Cell culture supernatants were tested for IL-10 concentrations using a mouse IL-10 ELISA kit according to manufacturer's instructions (eBioscience).

\section{In Vitro Suppression Assay}

Suppression assays were performed by culturing $\mathrm{CD} 4^{+} \mathrm{YFP}$ CD62L hi naive responder T cells $\left(2 \times 10^{4} /\right.$ well $)$ for $96 \mathrm{~h}$ with increasing numbers of $\mathrm{CD}^{+} \mathrm{YFP}^{+}$nTreg from Foxp3 reporter mouse lines $\left(0-2 \times 10^{4} /\right.$ well) in the presence of irradiated (30 Gray) splenic APCs and $1 \mu \mathrm{g} / \mathrm{ml}$ anti-CD3e. For the last $16 \mathrm{~h}$ of culture, $0.25 \mu \mathrm{Ci}$ of ${ }^{3} \mathrm{H}$-thymidine (Amersham Biosciences, Amersham, $\mathrm{UK}$ ) was added to each well and incorporation determined as mean counts per minute $(\mathrm{cpm})$ using a $\beta$-scintillation counter (Wallac, Turku, Finland).

\section{In Vivo Priming}

Host mice (CD45.2) received $2 \times 10^{6} \mathrm{CD} 4^{+}$OT-II T cells (CD45.1) i.v. 1 day prior to immunization with $20 \mu \mathrm{g}$ pOVA emulsified in complete Freund's adjuvant (CFA, containing $200 \mu \mathrm{g}$ heat-killed Mycobacterium tuberculosis $\mathrm{H} 37 \mathrm{Ra}$ ) (Sigma) in a final volume of $100 \mu \mathrm{l}$. Seven days after immunization, spleens and draining lymph nodes were isolated for flow cytometric analysis.

\section{Induction of Experimental Autoimmune Encephalomyelitis (EAE)}

Mice were immunized by subcutaneous injection of $100 \mu \mathrm{g}$ pMOG, emulsified in CFA in a final volume of $100 \mu$ l. Mice 
received 200-250 ng of Pertussis toxin in $500 \mu \mathrm{l}$ PBS i.p. on the same day as immunization and 2 days later (33). Clinical signs of EAE were scored daily using the following scoring system; 0 , no signs; 1 , flaccid tail; 2, impaired righting reflex and/or gait; 2.5 , impaired gait including notable but intermittent dragging of feet; 3, partial hind limb paralysis; 4, total hind limb paralysis; 5 , hind limb paralysis with partial forelimb paralysis; 6 , moribund or dead. Mice were sacrificed by $\mathrm{CO}_{2}$ asphyxiation at the latest 30 days after disease induction, or at an earlier time point to isolate organs for analysis. Assessment of CNS (brain and spinal cord) immune cells was conducted as described previously (34).

\section{T Cell Transfer Colitis}

Preventive model of $\mathrm{T}$ cell transfer colitis; $\mathrm{RAG}^{-1-}$ mice were injected i.v. with PBS or $5 \times 10^{5}$ naive wild-type (WT) $\mathrm{CD} 4^{+} \mathrm{T}$ cells $\left(\mathrm{CD} 4^{+} \mathrm{CD} 62 \mathrm{~L}^{\text {hiYFP}}\right)$ from Foxp $3^{\text {tm4(YFP/cre)Ayr }}$ mice in the presence or absence of $1.5 \times 10^{5}$ nTreg $\left(\mathrm{CD}^{+} \mathrm{YFP}^{+}\right)$from Foxp $3^{\text {tm4(YFP/cre)Ayr }}$ or Foxp3- $\alpha \mathrm{v}^{-/-}$mice in a total volume of $200 \mu \mathrm{l}$.

Curative model of $\mathrm{T}$ cell transfer colitis; $\mathrm{RAG}^{-1-}$ mice were injected i.v. with $\mathrm{PBS}$ or $5 \times 10^{5}$ naive $\mathrm{WT} \mathrm{CD} 4^{+} \mathrm{T}$ cells $\left(\mathrm{CD} 4{ }^{+} \mathrm{CD} 62 \mathrm{~L}^{\text {hiY YFP }}\right)$ from Foxp $3^{\text {tm } 4(\mathrm{YFP} / \mathrm{cre}) \text { Ayr }}$ mice, followed by i.v. injection of $2.5-8 \times 10^{5}$ nTreg $\left(\mathrm{CD}^{+} \mathrm{YFP}^{+}\right)$from the indicated Foxp3 reporter mice 21 days later. Mice were monitored daily and weighed three times a week until cull at 6-9 weeks after naive $\mathrm{T}$ cell transfer for analysis of spleen, mesenteric lymph nodes (MLNs), and colons. One half of the colonic tissue was used to isolate lymphoid cells from the lamina propria (LP). Briefly, the intestinal epithelial layer was removed by incubation in HBSS $2 \mathrm{mM}$ EDTA for $30 \mathrm{~min}$, and the remaining tissue digested with $1.25 \mathrm{mg} / \mathrm{ml}$ collagenase-4 (Worthington) and $30 \mu \mathrm{g} / \mathrm{ml}$ DNase- 1 (Roche) in culture medium and disaggregated with a gentle MACS dissociator (Miltenyi). Retrieved lymphoid cells were stained and analyzed by flow cytometry. The other half of colonic tissue was processed for staining by hematoxylin and eosin and assessed for colitis severity in a blinded fashion using the following scoring system for a maximum of 11 points; mucosal infiltration (0-3); submucosal infiltration (0-3); crypt loss (0-3); crypt abscesses (0-2).

\section{Antibodies and FACS Analysis}

Cells were stained with the following antibodies (all from eBioscience, except where stated); anti-CD4-BV650 (BioLegend, San Diego, CA, USA), anti-Foxp3-(ef450/FITC), anti-CD11bAF700 (Biolegend), anti- $\alpha \mathrm{V}-\mathrm{PE}$, anti-CD44-APC-Cy7, antiCD62L-PerCP-Cy5.5, anti-Ki-67-PE-Cy7, anti-KLRG1-ef450, anti-CD45.1-APC, anti-CD51-PE, anti-GM-CSF-PE, anti-IFN$\gamma$-APC, anti-IL-17-PerCPCy5.5. Rat IgG2a and rat IgG1, conjugated to respective fluorophores, were used as isotype control antibodies. For intracellular cytokine staining, cells were restimulated ex vivo with $20 \mu \mathrm{g} / \mathrm{ml}$ pOVA overnight, and Brefeldin $\mathrm{A}$ added for the last $4 \mathrm{~h}$ of incubation. Samples were stained with a fixable viability marker (conjugated with eFluor455, eBioscience) prior to surface staining. For subsequent intracellular antigen staining, samples were washed once in FACS buffer (PBS, 2\% FCS, $0.01 \% \mathrm{NaN}_{3}$ ) and then processed according to manufacturer's instructions (eBioscience for transcription factors, BD for intracellular cytokines). Flow cytometric data were acquired using a BD LSR Fortessa cell analyzer (BD) and data analyzed using FlowJo software (Treestar version 3.2.1, Ashland, OR, USA).

\section{Immunohistochemistry}

Paraffin-embedded longitudinal sections of the gut were cleared and rehydrated in xylene and graded alcohols, followed by antigen retrieval through pressure boiling in citrate buffer (Vector, Burlingame, CA, USA). Endogenous peroxidase activity was blocked with $3 \% \mathrm{H}_{2} \mathrm{O}_{2}$ (Fisher Scientific) in $\mathrm{dH}_{2} \mathrm{O}, 10 \%$ normal goat serum (Biosera, Boussens, France) in PBS was used to block unspecific binding sites, and endogenous avidin/biotin was blocked using an avidin-biotin blocking kit according to manufacturer's instructions (Vector). Samples were stained with biotinylated rat anti-mouse Foxp3 antibody (eBioscience, clone FJK-16s) and purified rabbit anti-mouse CD3 antibody (Abcam, polyclonal). Samples were then incubated with streptavidincoupled alkaline phosphatase (Vector) for $1 \mathrm{~h}$ at room temperature, washed, and Vector Blue substrate (SK-5300, Vector) added according to manufacturer's instructions. Samples were subsequently incubated with horseradish peroxidase-coupled goat anti-rabbit antibody, washed, and DAB working solution added according to manufacturer's instructions (Vector). Slides were mounted in Permafluor mounting medium (Thermo Scientific) prior to digitalization with an Axioscan.Z1 slide scanner (Carl Zeiss).

\section{Statistical Analysis}

Statistical analyses were performed using GraphPad Prism software (San Diego, CA, USA). In order to verify that data were normally distributed, Shapiro-Wilk normality tests were conducted. In experiments where data followed a Gaussian distribution, significance was tested using an unpaired Student's $t$-test when comparing two experimental groups, and a one-way ANOVA with Bonferroni's post hoc test when comparing three or more experimental groups. When $n$ numbers were not sufficient to test for normality, or when data proved not to be normally distributed, the non-parametric Mann-Whitney test (comparing two groups) or the non-parametric Kruskal-Wallis test with Dunn's post hoc test (three or more groups) were applied. Due to the ranked nature of EAE disease scores and disease length, the non-parametric Kruskal-Wallis test with Dunn's post hoc test was used to determine differences between three or more groups. When examining the effect of two factors on the experimental outcome, a two-way ANOVA was applied with Bonferroni's post hoc test where applicable. Data were considered significantly different with $p$-values of $<0.05\left({ }^{*} p<0.05\right.$, ${ }^{* *} p<0.01$, and $\left.{ }^{* * *} p<0.001\right)$.

\section{RESULTS}

\section{Treg at Sites of Inflammation Express High Levels of the Integrin $\alpha v$}

Experimental autoimmune encephalomyelitis is a useful experimental model to compare the function and behavior of $\mathrm{CD}^{+}$ 
$\mathrm{T}$ cells, including Treg, retrieved from the site of autoimmune inflammation (in this case the CNS) versus those from the secondary lymphoid organs of the same mouse. We have previously documented that Treg retrieved from the inflamed CNS display a suppressive potency that is markedly superior to that of their splenic counterparts (35). Here, we sought to understand any causative association between this elevated Treg function and their expression of $\alpha \mathrm{v}$ integrins. Treg retrieved from the inflamed CNS shortly after peak of disease (Figures 1A,B) exhibited markedly higher surface $\alpha \mathrm{v}$ expression levels compared to Treg in the spleen and inguinal lymph nodes (iLNs) (Figures 1C,D). Treg surface $\alpha \mathrm{v}$ expression levels were also higher compared to effector T cells, in both spleen and CNS (Figure 1D). These differences were confirmed at the mRNA level using qPCR of sorted $\mathrm{CD}^{+} \mathrm{T}$ cell populations (Figure 1E).

To understand whether increased $\alpha v$ expression was a more general feature of Treg exposed to inflammation, we investigated $\alpha \mathrm{v}$ expression patterns in a curative $\mathrm{T}$ cell transfer model of colitis. Treg were injected into $\mathrm{RAG}^{-/-}$mice 3 weeks after disease induction and colon LP, mLNs, and spleen harvested 6 weeks later (Figures 1F,G). Following an initial weight loss typical for $\mathrm{T}$ cell induced colitis, mice treated with Treg started regaining weight about 1 week post-Treg injection, indicative of the immunosuppressive activity of the injected Treg. Again, Treg found in the colon LP expressed $\alpha \mathrm{v}$ at markedly higher levels than their splenic and mLN counterparts, as well as their Foxp3- counterparts (Figures 1H,I), suggesting that Treg at sites of inflammation may generally exhibit enhanced $\alpha \mathrm{v}$ expression levels.

\section{Treg Homeostasis Is Not Dependent on $\alpha v$ Integrins}

In order to test whether $\alpha \mathrm{v}$ integrins are required by Treg to maintain immune homeostasis, we generated conditional Foxp3- $\alpha \mathrm{v}^{-1-}$ mice lacking $\alpha \mathrm{v}$ specifically in Foxp $3^{+}$cells by

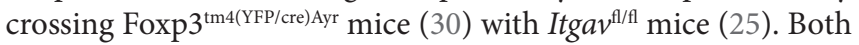
naive $\mathrm{CD} 4^{+} \mathrm{T}$ cells and Treg from Foxp $3^{\text {tm4(YFP/cre)Ayr }}$ control mice expressed $\alpha \mathrm{v}$ (Figure 2A). As expected, surface $\alpha \mathrm{v}$ expression was absent specifically among Treg from Foxp $3-\alpha v^{-/-}$mice (Figures 2A,B). Importantly, proportions of Treg in spleen, lymph nodes and colon LP remained unaltered in the absence of Treg $\alpha v$ integrins (Figure 2C), indicating that $\alpha v$ integrins are not involved in Treg maturation and homeostasis. Treg from Foxp3$\alpha \mathrm{v}^{-/-}$mice and Foxp $3^{\text {tm4(YFP/cre)Ayr }}$ control mice displayed comparable $\mathrm{CD} 62 \mathrm{~L}$ and $\mathrm{CD} 44$ expression in the steady state, indicating unaltered activation status in the absence of $\alpha \mathrm{v}$ integrins (Figure S1A in Supplementary Material). Similarly, Ki-67 levels were indistinguishable between control and $\alpha \mathrm{v}^{-/-}$nTreg, suggesting no alteration in cell cycle progression and hence proliferative potential in these cells (Figure S1B in Supplementary Material). Foxp3 expression levels within the Foxp $3^{+}$Treg pool were also comparable between control and Foxp3 $-\alpha \mathrm{v}^{-/-}$mice (Figure S1C in Supplementary Material).

In order to verify that the deletion of the Itgav gene occurred upon induction of Foxp3, iTreg were generated from naive CD4 ${ }^{+}$ $\mathrm{T}$ cells of Foxp $3^{\mathrm{tm} 4(\mathrm{YFP} / \mathrm{cre}) \text { Ayr }}$ control and Foxp3- $\mathrm{\alpha v}^{-1-}$ mice for
5 days. $>50 \%$ of naive $\mathrm{CD} 4{ }^{+} \mathrm{T}$ cells in both groups expressed $\alpha \mathrm{v}$ at the start of culture. At the end of culture, $>95 \%$ of the cells in both groups expressed Foxp3 (Figure 2D). Surprisingly, $\alpha \mathrm{v}$ expression was downregulated on all cells over the course of 5 days in iTreg culture (Figure 2E). However, upon replenishment of culture media without TGF- $\beta$ for 2 days, control iTreg readily recovered $\alpha \mathrm{v}$ expression, while Foxp3- $\alpha \mathrm{v}^{-1-}$ iTreg were unable to do so (Figure 2E). This demonstrated that the ability to express $\alpha \mathrm{v}$ in $\mathrm{CD}^{+} \mathrm{T}$ cells was lost upon Foxp3 induction in these conditional knockout mice.

Considering the marked impact of iTreg culture conditions on $\alpha \mathrm{v}$ expression in these cells, this phenomenon was further examined. Stimulation of naive $\mathrm{T}$ cells, in the absence of active TGF- $\beta$, did not result in a loss of $\alpha \mathrm{v}$ expression (Figure S1D in Supplementary Material), suggesting that the presence of active TGF- $\beta$ during culture caused downregulation of $\alpha$ v. Since stimulation of naive $\mathrm{T}$ cells in the presence of TGF- $\beta$ led to reduced $\alpha \mathrm{v}$ expression even in $\mathrm{CD} 4^{+} \mathrm{T}$ cells not expressing Foxp3 within 5 days (Figure S1E in Supplementary Material), downregulation of $\alpha v$ was unlikely a secondary effect of Foxp3 induction. A similar effect was observed in nTreg, whereby nTreg stimulated in the presence of active TGF- $\beta$ for 3 days displayed significantly lower levels of $\alpha \mathrm{v}$ compared to nTreg stimulated in the absence of active TGF- $\beta$ (Figure S1F in Supplementary Material). Loss of surface $\alpha \mathrm{v}$ through the presence of TGF- $\beta$ was partially prevented by the addition of a TGF- $\beta$ type I receptor (ALK5) kinase inhibitor, supporting the idea that TGF- $\beta$ signaling itself led to $\alpha$ v downregulation.

\section{Treg Do Not Require $\alpha v$ Expression in Order to Suppress the Activation and Proliferation of Conventional T Cells}

Conventional CD4 $4^{+} \mathrm{T}$ cells in spleen, iLN, mLN, and colon LP of Foxp $3^{\text {tm4(YFP/cre)Ayr }}$ control mice and Foxp3- $\alpha \mathrm{v}^{-/-}$mice displayed a similar activation status and proliferative activity (Figures S2A,B in Supplementary Material), indicating normal Treg activity in the absence of $\alpha \mathrm{v}$ integrins under steady state. Indeed, Foxp3$\alpha \mathrm{v}^{-/-}$mice did not develop a spontaneous inflammatory disorder when left to age up to 10 months (data not shown). Consistent with this, no differences were found in the ability of nTreg from $\alpha \mathrm{v}^{-/-}$or Foxp3 $3^{\mathrm{tm} 4(\mathrm{YFP} / \mathrm{cre}) \text { Ayr }}$ mice to inhibit responder T cell proliferation using an in vitro suppression assay (Figure 3A). Likewise, iTreg generated from Foxp $3-\alpha v^{-/-}$mice showed no impairment in suppressive activity in vitro (data not shown). The secretion of IL-10, a major Treg-derived immunosuppressive cytokine, was also not impaired in $\alpha \mathrm{v}^{-1-}$ Treg upon in vitro stimulation (Figure 3B).

To test Treg suppressive function in vivo, Foxp3- $\alpha \mathrm{v}^{-/-}$and Foxp $3^{\text {tm4(YFP/cre)Ayr }}$ control mice were seeded with CD $4^{+} \mathrm{CD} 45.1^{+}$ $\mathrm{T}$ cells from OT-II mice prior to immunization with pOVA. Proportions and total numbers of CD $45.1^{+}$donor cells that had subsequently accumulated in the spleen or draining lymph nodes did not differ between Foxp3- $\alpha \mathrm{v}^{-/-}$and control mice (Figures 3C,D, data not shown). Also, no difference was observed in donor cell activation and proliferation status (Figures S3A,B in Supplementary Material), and pro-inflammatory cytokine 
A Disease course

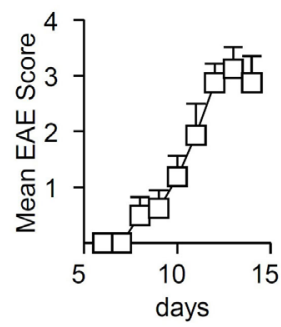

B

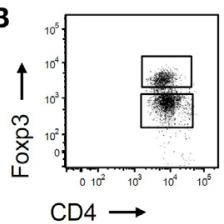

C

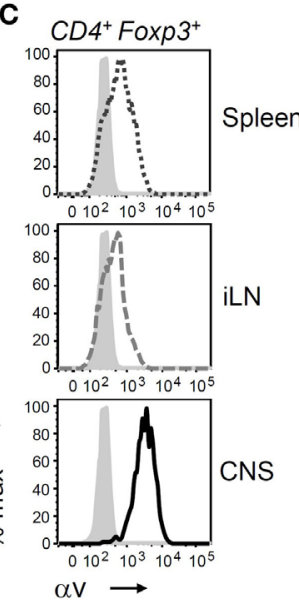

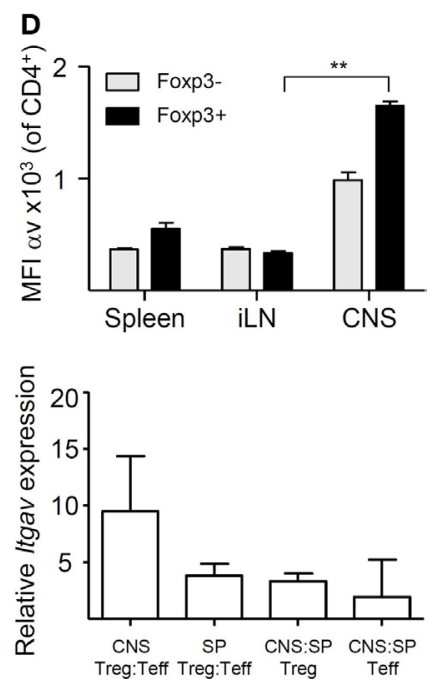

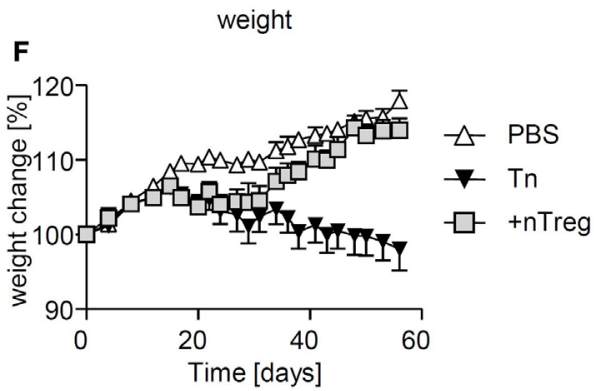

G

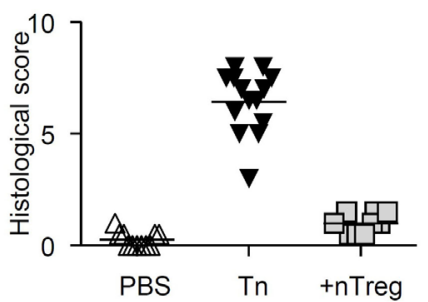

H

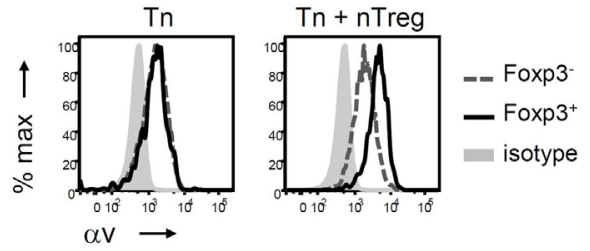

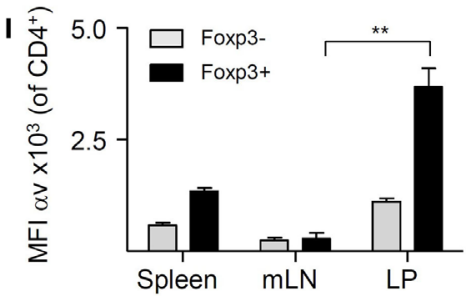

FIGURE $1 \mid \alpha v$ is highly expressed on regulatory T cells (Treg) at sites of inflammation experimental autoimmune encephalomyelitis (EAE) was induced in Foxp3 $3^{\text {tmA(YFP/(cre)Ayr }}$ mice by immunization with 35-55 peptide of mouse myelin oligodendrocyte glycoprotein (pMOG), and spleen, inguinal lymph nodes (iLN), and central nervous system (CNS) harvested shortly after peak of disease ( $n=8$, pooled from two experiments). (A) Mean clinical scores + SEM. (B) Representative dot plot for gating of $\mathrm{CNS} \mathrm{Foxp3}^{+}$and Foxp3- $\mathrm{CD}^{+} \mathrm{T}$ cells. (C) Representative plots of $\alpha v$ expression on Treg retrieved from different organs. (D) $\alpha v$ expression levels on Treg in comparison to conventional T cells in different organs ( $n=4$, representative of two experiments). (E) Relative mRNA expression levels of $\alpha v$ in Treg and conventional T cells in CNS and spleen of EAE mice. (F) Colitis was induced by injection of naive T cells $(\mathrm{Tn})$ into RAG1//- mice and curative CD4+ Foxp3 ${ }^{+} \mathrm{T}$ cells (nTreg) were injected 21 days later $(n=10-14$ mice per group, pooled from two experiments). Spleen, mesenteric lymph nodes (mLNs) and colon lamina propria (LP) were harvested 8 weeks after disease induction. (G) Histological colitis score. (H) Representative histograms showing $\alpha \mathrm{V}$ expression on Foxp3 ${ }^{+}$and Foxp3- CD4 ${ }^{+}$T cells in the LP of colitis mice. (I) $\alpha$ v expression levels on Treg in comparison to conventional T cells in different organs $(n=4$, representative of two experiments).

expression upon re-stimulation with cognate antigen ex vivo was comparable between groups (Figure 3E). Similarly, $\alpha \mathrm{v}$ integrins were not required for Treg suppressive activity in a preventive model of T cell transfer colitis. $\alpha \mathrm{v}^{-1-}$ Treg co-injected with disease-inducing naive $\mathrm{CD} 4^{+} \mathrm{T}$ cells from Foxp $3^{\text {tm4(YFP/cre)Ayr }}$ mice were as capable of preventing pathological changes of the colon and associated weight loss as control Treg (Figures 3F,G). Notably, immunohistochemical staining of Foxp $3^{+}$cells demonstrated comparable numbers of control and $\alpha \mathrm{v}^{-1-}$ Treg in the colon LP of these mice (Figures 3H,I). Collectively, these data indicate that Treg $\alpha \mathrm{v}$ integrins play no critical role in their capacity to limit inflammation initiated by the activities of $\mathrm{CD} 4^{+}$ T cells.

\section{$\alpha \mathbf{v}^{-1-}$ Treg Can Migrate to the Inflamed CNS and Resolve EAE}

The integrin $\alpha v \beta 8$ has been recently proposed to be essential for Treg function at sites of inflammation through the activation of latent TGF- $\beta$ (28). During EAE, CNS Treg exhibit a highly activated phenotype $(34,35)$, and Treg are crucial in mediating the resolution of disease (35-37). While $\alpha v$ integrins appeared 

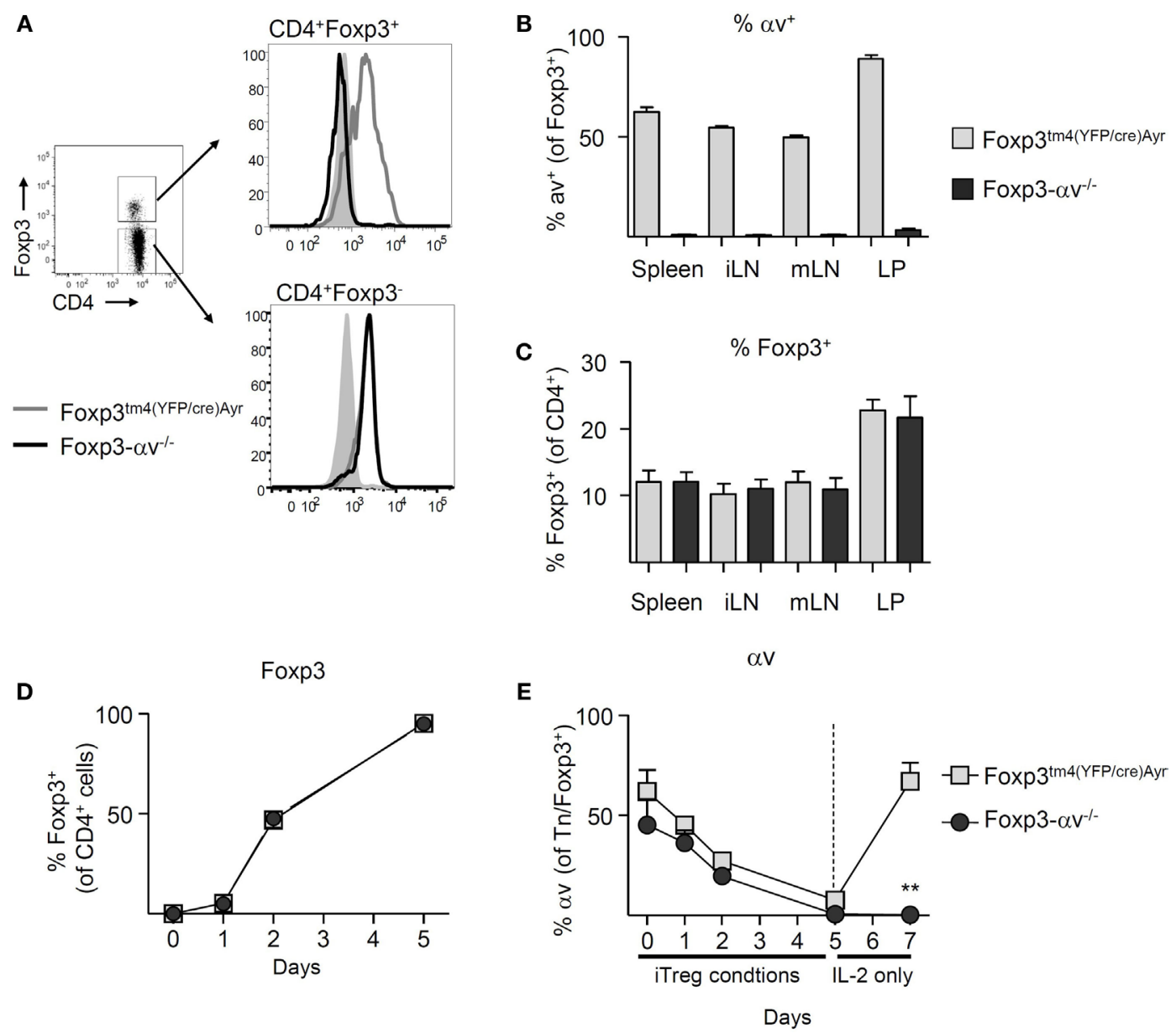

FIGURE 2 | Basic characterization of regulatory T cells (Treg) from Foxp3- $\alpha \mathrm{V}^{-/-}$mice. (A) Representative histograms of $\alpha v$ expression in Foxp3 $3^{+}$and Foxp3- CD4+

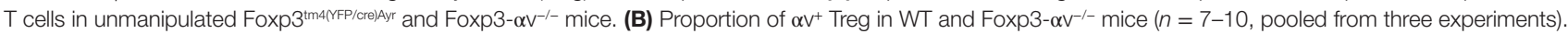

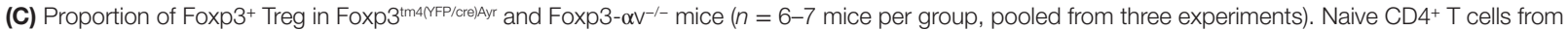
Foxp3 $3^{\text {tm4(FF/(re)Ayr }}$ and Foxp3- $\alpha V^{-1-}$ mice were cultured under iTreg generating conditions and (D) Foxp3 expression assessed over time ( $n=6$ mice per group, pooled from two experiments). iTreg were rested in IL-2 for 2 days and (E) proportion of Foxp $3^{+}$iTreg (naive T cells on d0) expressing $\alpha \vee$ determined over time.

redundant for Treg homeostasis and Treg-mediated prevention of inflammation, it remained to be determined whether the observed elevated levels of $\alpha \mathrm{v}$ on CNS Treg (Figures 1C-E) had a functional consequence for resolution of EAE. The role of $\alpha \mathrm{v}$ integrins, and particularly the integrin $\alpha \mathrm{v} \beta 8$, in Treg function during EAE was explored in Foxp $3^{\text {tm4(YFP/cre)Ayr }}$, Foxp3- $\alpha \mathrm{v}^{-1-}$ and Foxp3- $\beta 8^{-1-}$ mice, following immunization with pMOG. The clinical courses and mean maximal EAE scores were indistinguishable between all three mouse lines (Figures 4A,B), indicating no requirement for $\alpha \mathrm{v}$ integrins in Treg-dependent resolution of EAE. Shortly after peak of disease, $\alpha \mathrm{v}^{-/}$and $\beta 8^{-/-}$Treg were found at similar proportions in the CNS as WT Treg (Figures 4C,D), excluding a critical role for $\alpha \mathrm{v}$ integrins in Treg migration into the inflamed CNS. CNS Treg in all three mouse lines displayed an effector Treg phenotype, with high CD44 and low CD62L expression, high cell cycle activity and heightened KLRG1 expression, compared to their peripheral counterparts (Figures S4A-C in Supplementary Material).

\section{Impaired Accumulation of $\alpha v^{-1-}$ Treg in the Inflamed Gut and Quantitative Defect to Cure T Cell-Induced Colitis}

Although Treg are critical to the immune processes that ultimately lead to the resolution of EAE, it remains unclear whether this non-redundant influence is exerted solely by those Treg that accumulate in the inflamed CNS, or whether an alternative, earlier effect of restraining pathogenic $\mathrm{T}$ cell expansion during the priming stages of EAE in the peripheral lymphoid organs is also required, or even indispensable. To more specifically address the activity of Treg once inflammatory pathology was established, we chose the curative model of $\mathrm{T}$ cell transfer colitis, whereby Treg are injected into $\mathrm{RAG1}^{-/-}$after disease onset (38), and control of colonic inflammation can only occur if Treg migrate to the site of inflammation.

$\mathrm{T}$ cell transfer colitis was induced in $\mathrm{RAG}^{-/-}$mice, and Foxp $3^{\mathrm{tm} 4(\mathrm{YFP} / \mathrm{cre}) \mathrm{Ayr}}, \alpha \mathrm{v}^{-/-}$or $\beta 8^{-/-}$Treg were injected at $2.5 \times 10^{5}$ cells per mouse 21 days later. Both the control Treg-treated 
A ชู

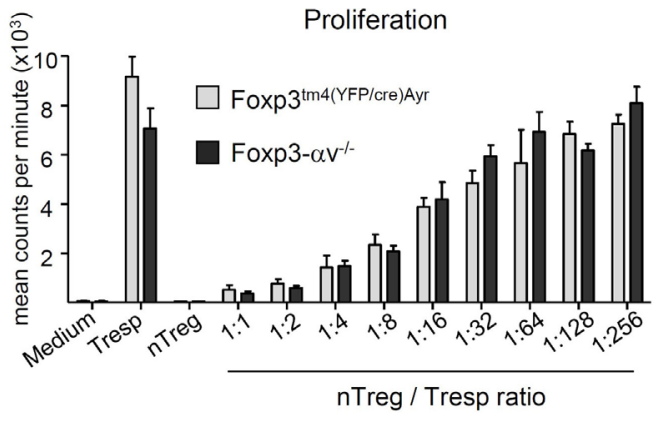

C

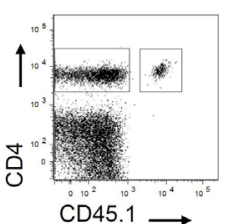

D

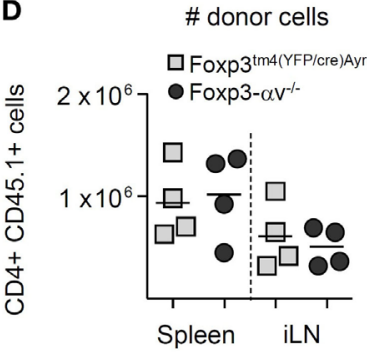

B

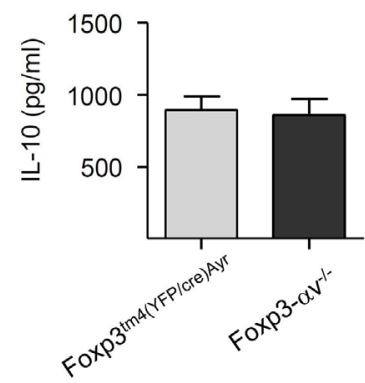

$\mathbf{E}$

Cytokine expression

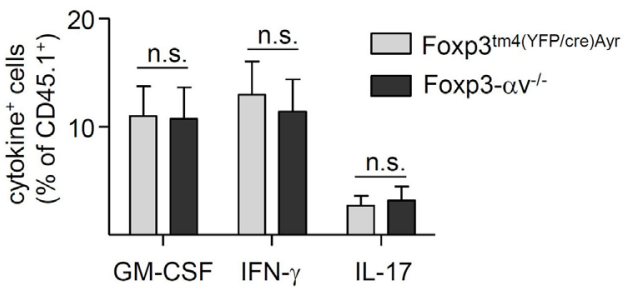

G

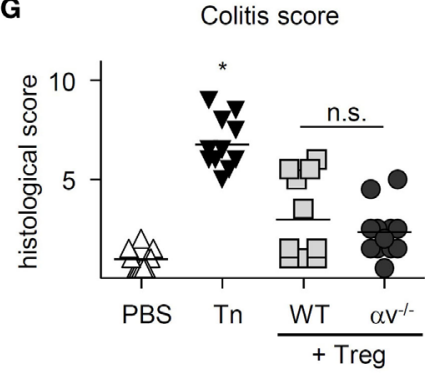

I

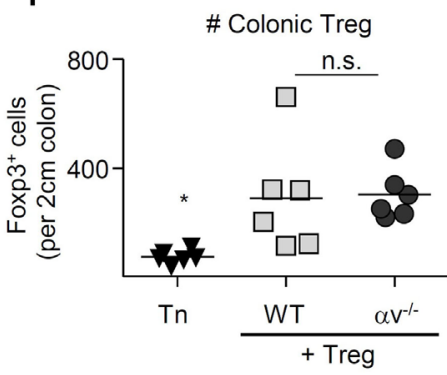

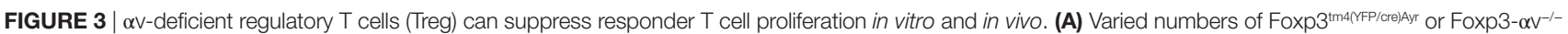

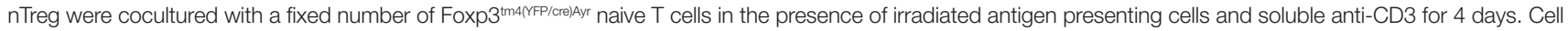

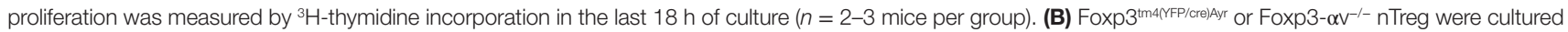
with mouse T-Activator Dynabeads at a 1:1 ratio for 3 days in the presence of 1,000 U/ml IL-2, and IL-10 concentrations measured in the culture supernatant by

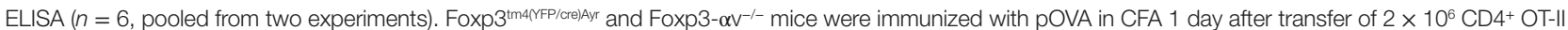
responder cells (CD45.1), and organs harvested 7 days later. (C) Gating strategy for host (CD45.1 $)$ and donor (CD45.1 $\left.1^{+}\right)$CD4+ $T$ cells and (D) total numbers of donor cells retrieved from spleen and inguinal lymph nodes (iLNs). (E) Splenocytes were restimulated with $20 \mu \mathrm{g} / \mathrm{ml}$ pOVA overnight and cytokine expression analyzed by

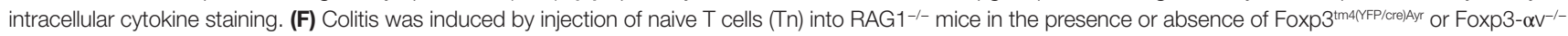
nTreg and weight assessed over time ( $n=11-12$ mice per group, pooled from two experiments). (G) Histological colitis score 6 weeks after disease induction (range $=0-11$. $(\mathbf{H})$ Colon sections were stained with anti-Foxp3 (see black arrows) and anti-CD3 antibodies and visualized with Vector Blue substrate and DAB, respectively. (I) Numbers of Foxp3 ${ }^{+}$cells were counted in a $2 \mathrm{~cm}$ long longitudinal section of the colon, starting $2 \mathrm{~cm}$ proximal of the anus ( $n=6$ per group).

and the $\beta 8^{-/-}$Treg-treated mice began regaining weight around 3 weeks after Treg injection (Figure 5A). However, $\alpha v^{-1-}$ Tregtreated mice failed to regain weight (Figure 5A), translating into no weight gain from the time of Treg injection, compared to mice receiving either control or $\beta 8^{-/-}$Treg (Figure 5B). Consistent with this, histological severity of colitis differed significantly between 

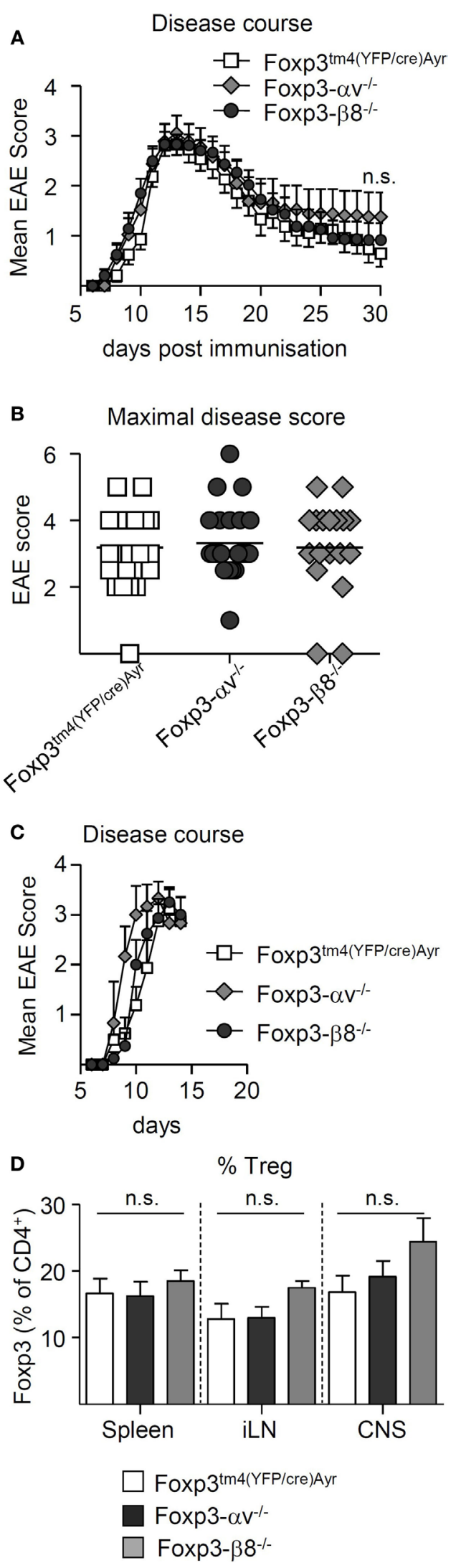

FIGURE 4 | Continued
FIGURE $4 \mid \alpha$-deficient regulatory T cells (Treg) are able to migrate to the inflamed central nervous system (CNS) and resolve experimental autoimmune encephalomyelitis (EAE). EAE was induced in Foxp3 $3^{\text {tm4(NFP/(re)Ayr }}$, Foxp3- $\alpha V^{-1-}$, and Foxp3- $\beta 8^{-/-}$mice by immunization with $\mathrm{PMOG}$ and mice monitored up to 30 days. (A) Mean clinical scores \pm SEM and (B) maximal disease scores ( $n=18-24$ mice per group, pooled from four experiments). EAE was induced as above and spleen, inguinal lymph nodes (iLNs), and CNS harvested shortly after peak of disease ( $n=3-8$, pooled from two experiments).

(C) Mean clinical scores + SEM. (D) Proportion of Treg in indicated organs.

groups (Figures 5C,D); while mice receiving control Treg and $\beta 8^{-1-}$ Treg had relatively low colitis scores, those receiving $\alpha \mathrm{v}^{-/-}$ Treg had disease scores which did not differ from diseased mice that received no Treg treatment. This failure of ${\alpha \mathrm{v}^{-1-}}^{-T}$ Treg to cure colitis was associated with significantly reduced Treg proportions and numbers in the LP (Figure 5E; Figure S5A in Supplementary Material). In contrast, Treg proportions and numbers in the spleen and $\mathrm{mLN}$ were not reduced (Figures S5B-E in Supplementary Material). However, the proportion of Treg expressing Ki-67 as well as Foxp3 expression levels of Treg in the LP did not differ between groups (Figures 5F,G), suggesting that neither reduced Treg proliferation nor Foxp3 instability were the cause of the observed lower $\alpha \mathrm{v}^{-1-}$ Treg proportions in the LP. Finally, at a higher number of curative Treg $\left(8 \times 10^{5}\right)$ injected 21 days postdisease induction, control and $\alpha^{-1-}$ Treg were equally able to reverse disease (Figures 6A-C). While a significantly reduced proportion of $\alpha^{-/-}$Treg in the colon LP was still apparent at harvest (Figure 6D), they represented an average $5.4 \%$ of the colonic $\mathrm{CD}^{+} \mathrm{T}$ cell population versus $2.2 \%$ in the first curative colitis experiment. This suggests that a quantitative, rather than qualitative, deficit was responsible for the observed inability of

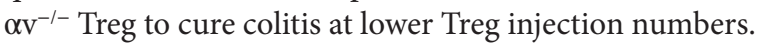

\section{DISCUSSION}

Our findings highlight the tissue- and context-specific requirement for Treg $\alpha v$ integrins in optimal Treg function. $\alpha v$ integrins were not required for Treg to migrate to the inflamed CNS during $\mathrm{EAE}$ and resolve disease. Furthermore, $\alpha \mathrm{v}^{-1-}$ Treg were able to prevent $\mathrm{T}$ cell transfer colitis. However, during a curative $\mathrm{T}$ cell transfer model of colitis, $\alpha \mathrm{v}^{-/}$Treg were detected at significantly lower proportions and numbers in the inflamed gut, and this correlated with an impairment in the ability of $\alpha \mathrm{v}^{-1-}$ Treg to resolve colitis compared to WT Treg.

\section{$\alpha v$ Integrins Are Crucial for Treg Accumulation in the Inflamed Gut}

The curative model of $\mathrm{T}$ cell transfer colitis is a useful tool to assess whether Treg can migrate to the already established site of inflammation in the periphery and resolve ongoing inflammation. When injecting naive $\mathrm{CD} 4^{+} \mathrm{T}$ cells alone, a small proportion of these cells are converted into Foxp3 expressing peripherally induced Treg in the gut (39). Mice receiving $2.5 \times 10^{5} \mathrm{\alpha v}^{-/-}$Treg showed similar proportions and numbers of Foxp $3^{+}$cells in the colon LP as control mice that received no Treg injection, associated with a failure to reverse disease. While injection of a higher 

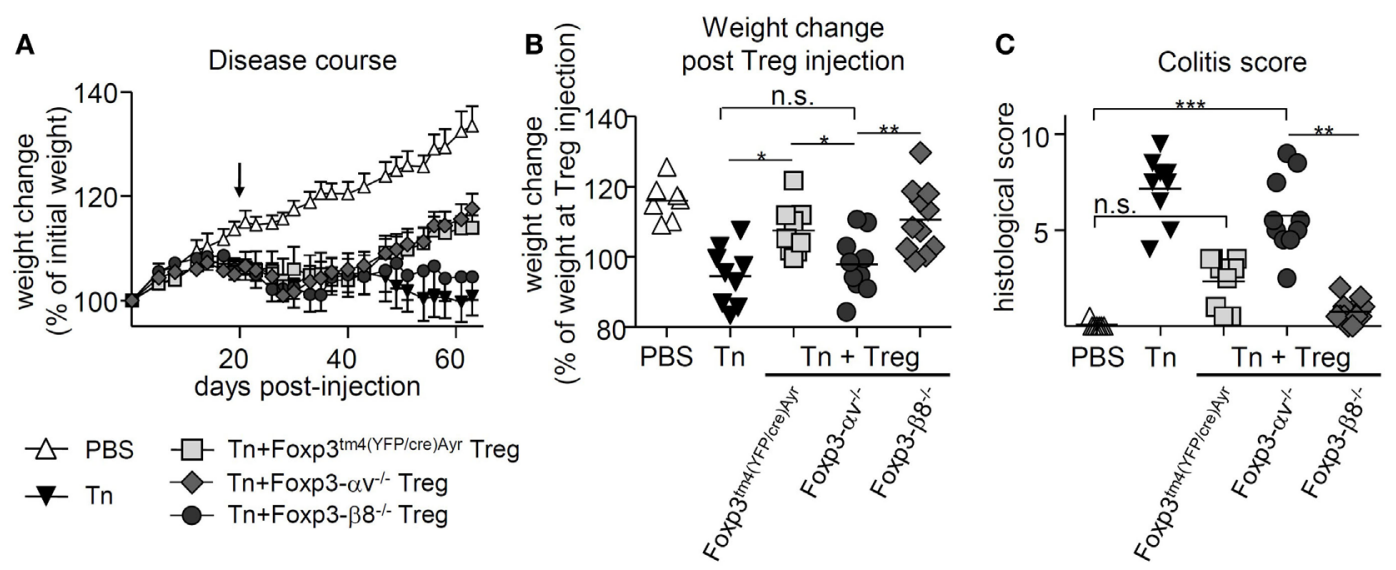

D
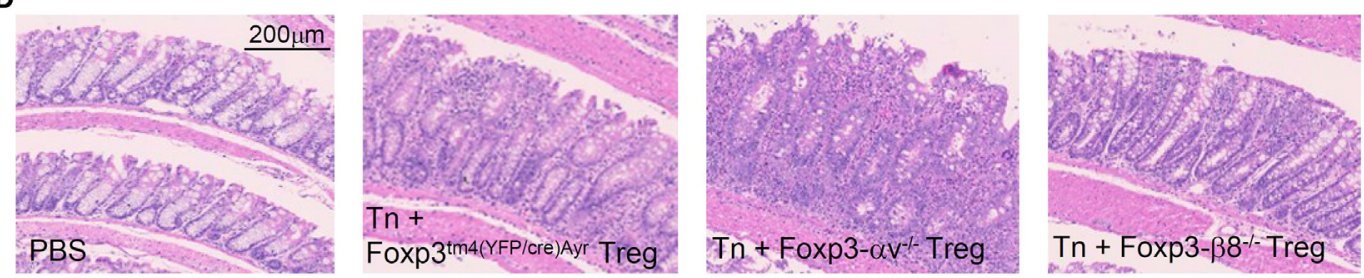

E
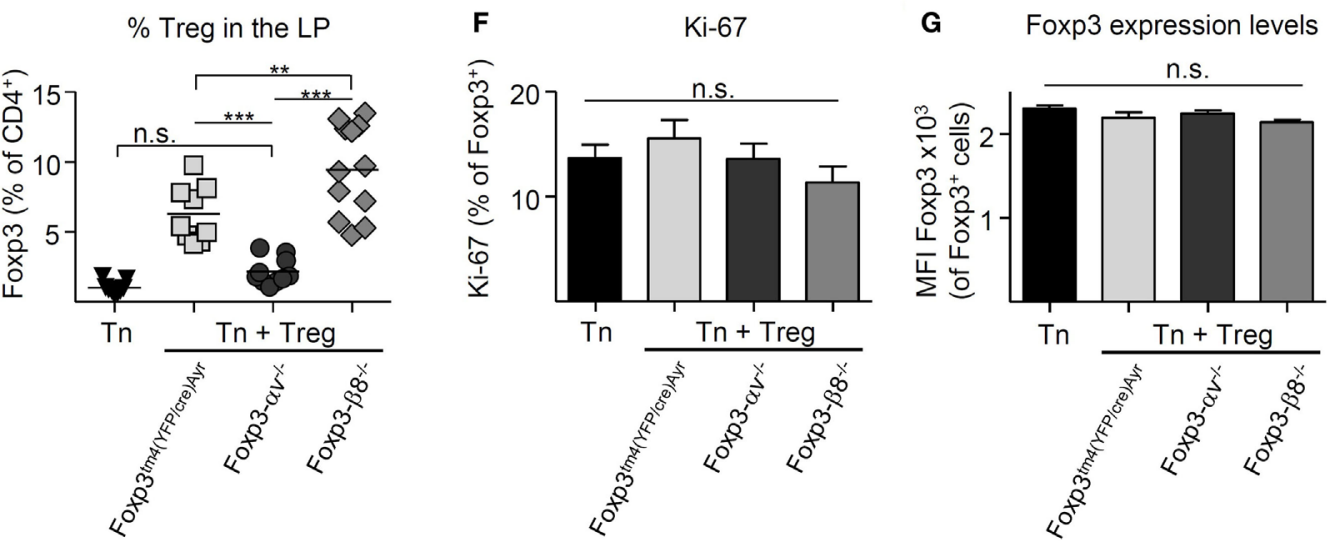

FIGURE 5 | Regulatory T cells (Treg) lacking all $\alpha$ v integrins are unable to cure T cell-induced colitis due to attenuated accumulation in the inflamed gut. Colitis was induced by injection of naive T cells (Tn) into RAG1 ${ }^{-/-}$mice, and $2.5 \times 10^{5}$ nTreg from Foxp3 ${ }^{\text {tm4(YFP/cre)Ayr }}$, Foxp3- $\alpha V^{-/-}$, or Foxp3- $\beta 8^{-/-}$mice injected 21 days later ( $n=7-12$ mice per group, pooled from two experiments). Spleen, mesenteric lymph nodes (mLN), and colon lamina propria (LP) were harvested 9 weeks after disease induction. Weight change $\mathbf{( A )}$ over time and $\mathbf{( B )}$ at harvest relative to weight at nTreg injection. $(\mathbf{C})$ Histological colitis score (range $=0-11)$ and (D) representative H\&E-stained sections of the colon LP. Proportion of (E) Treg and (F) Ki-67+ Treg in the colon LP. (G) Foxp3 expression levels of Treg in the colon LP ( $n=4-6$, representative of two experiments).

number $\left(8 \times 10^{5}\right)$ of curative $\alpha \mathrm{v}^{-/-}$Treg resulted in a greater proportion of Treg in the colon LP and the ability to resolve disease, the deficit in Treg accumulation in the colon in the absence of $\alpha \mathrm{v}$ compared to WT Treg was still apparent. Integrins have been implicated in the migratory capacity of many cell types (40). However, subsets of $\mathrm{CD}^{+} \mathrm{T}$ cells do not share all migratory pathways, with integrin $\alpha 4$ being critical for Th1 cell entry into the CNS during EAE while being redundant for Treg entry (19). Instead, Treg rather depend on $\alpha \mathrm{L}$ to cross the blood-brain barrier. Mechanisms of Treg migration may also be tissue-specific, since Treg found in different tissues have a distinct gene expression profile, adapted to the respective environment (4, 41-44). It is therefore not surprising that in a different experimental model of tissue inflammation, namely EAE, $\alpha \mathrm{v}^{-/-}$Treg were found to accumulate at expected levels in the inflamed CNS. Overstreet et al. reported no role for $\alpha \mathrm{v}$ integrins in effector $\mathrm{T}$ cell migration from lymph nodes into the inflamed skin (23). However, ECM changes during inflammation promoted a role for $\alpha \mathrm{v}$ integrins in interstitial movement within the skin, thereby aiding clearance of infection. Since $\alpha v$ integrins are able to recognize several components of the ECM, a role in controlling migration in inflamed versus non-inflamed tissue is conceivable. This is further supported by the observation that $\alpha \mathrm{v}^{-/-}$Treg were found at comparable levels to control Treg in the colon during the 
A

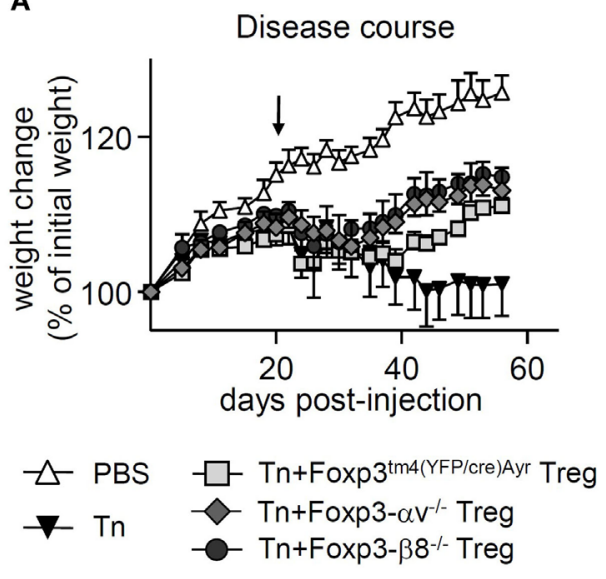

C

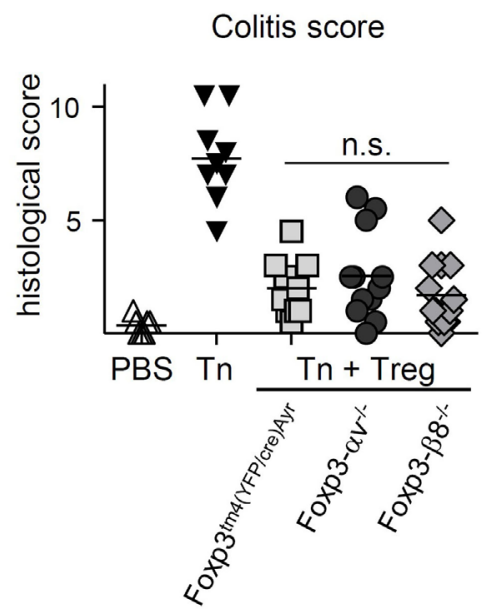

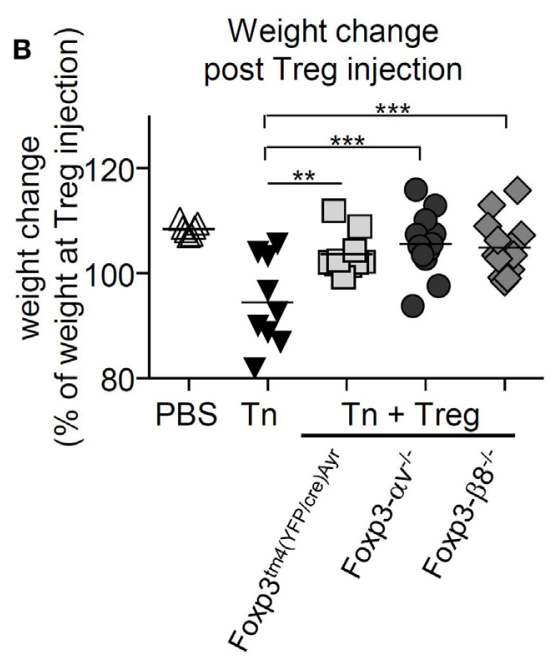

D $\%$ Treg in the LP

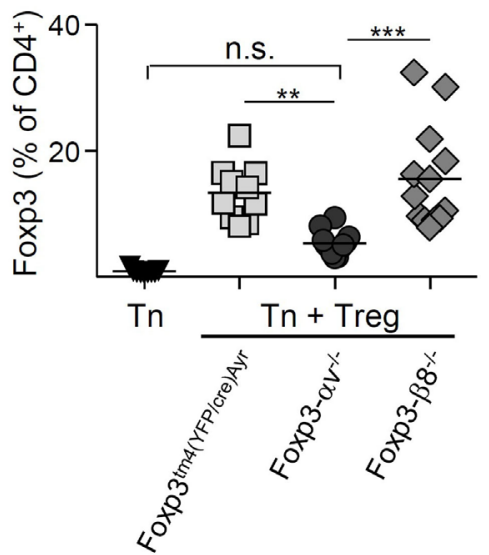

FIGURE 6 | High numbers of injected $\alpha$-deficient regulatory T cells (Treg) allow for disease resolution in T cell-induced colitis. Colitis was induced by injection of naive T cells (Tn) into RAG1 ${ }^{-/-}$mice, and $8 \times 10^{5}$ nTreg from Foxp3 $3^{\text {tm4(YFP/cre)Ayr }}$, Foxp3- $\alpha v^{-/-}$, or Foxp3- $\beta 8^{-/-}$mice injected 21 days later $(n=9-13$ mice per group, pooled from two experiments). Spleen, mesenteric lymph nodes (mLN), and colon lamina propria (LP) were harvested 9 weeks after disease induction. Weight change (A) over time and (B) at harvest relative to weight at nTreg injection. (C) Histological colitis score (range $=0-11)$ and (D) proportion of Treg in the colon LP.

preventive model of $\mathrm{T}$ cell transfer colitis. In this model, coinjection of Treg and naive $\mathrm{CD} 4^{+} \mathrm{T}$ cells allows for Treg to migrate through and populate uninflamed tissue, unlike in the curative model. This does not exclude a potential role for $\alpha \mathrm{v}$ integrins in the survival (10), Foxp3 stability (45), and expansion of Treg (34) in the inflamed colon, which have all been implicated in defining Treg accumulation in other contexts. Unaltered Treg numbers in secondary lymphoid organs and the CNS, in the case of EAE, does not preclude the possibility that $\alpha \mathrm{v}$ integrins are required for Treg survival in the inflamed gut, since different Treg subsets have been reported to depend on specific survival signals, such as ICOS in the case of effector Treg (10) and IL-2 in the case of central Treg $(46,47)$. While we confirmed comparable Foxp3 and Ki-67 levels in colonic Treg, arguing against altered Treg stability and local expansion, respectively, the data reflect only the circumstances of the time point analyzed. However, there is strong evidence that $\alpha \mathrm{v}^{-1-}$ Treg have no functional deficit in their immunosuppressive capacity. This is supported by their ability to suppress activation of responder $\mathrm{T}$ cells in vitro as well as in several in vivo models to the same extent as WT Treg, and their equal expression of IL-10 upon activation-a cytokine crucial for Treg function in homeostasis (30), EAE (36) and the curative $\mathrm{T}$ cell transfer colitis model (48). Furthermore, the inability of $\alpha \mathrm{v}^{-1-}$ Treg to cure colitis was based on their negligible numbers in the inflamed colon, with Treg numbers being below a threshold that could confer immunosuppression. When a higher number of Treg was injected, leading to a relative increase in $\alpha \mathrm{v}^{-/-}$Treg found in the colon, Treg numbers appeared sufficient to suppress ongoing inflammation and mice recovered from colitis equally, whether $\alpha \mathrm{v}^{-/-}$or WT Treg had been injected. In summary, while definitive identification of the prevalent mechanism requires further investigation, data presented here suggest that $\alpha \mathrm{v}$ integrins 
play an important role in Treg accumulation, but not function, specifically in the inflamed gut.

\section{$\alpha v$ Integrins Are Not Required for Treg Development and Immune Homeostasis}

Despite the severe functional deficiency of Treg in the inflamed gut in the absence of $\alpha \mathrm{v}$, conditional Foxp3- $\alpha \mathrm{v}^{-/-}$mice were healthy and retained a normal Treg compartment in the steady state, including in the colon LP. This indicates that $\alpha \mathrm{v}$ integrins are not required for Treg development, nor for homing and maintenance in the colon under homeostatic conditions. Global knockout of $\alpha \mathrm{v}$ leads to early lethality in mice due to placental defects and defects in brain vasculogenesis leading to intracerebral hemorrhages (49). However, this phenotype is not due to lack of $\alpha \mathrm{v}$ on lymphocytes, since conditional Lck- $\alpha \mathrm{v}^{-/-}$mice did not present with spontaneous autoimmune disease (25). We can further confirm that lack of $\alpha v$ integrins on Treg did not result in disturbed immune homeostasis in mice left to age up until 10 months of age. Therefore, $\alpha v$ integrin expression by Treg plays a far minor role in immune homeostasis than on DCs; mice lacking $\alpha \mathrm{v} \beta 8$ on DCs develop spontaneous colitis (25) due to the inability of $\mathrm{CD}_{103}{ }^{+}$DCs to activate latent TGF- $\beta$ and thereby induce adaptive Treg in the gut (26). We also found no role for $\alpha v$ integrins in Treg-mediated control of the initiation of an immune response, using an in vitro suppression assay, in vivo priming, and a preventive model of $\mathrm{T}$ cell transfer colitis. This highlights the context dependency of the functional relevance of Treg $\alpha \mathrm{v}$ integrins. While $\alpha \mathrm{v}^{-1-}$ Treg were capable of migrating to the colon in the preventive model of $\mathrm{T}$ cell transfer colitis, Treg are not needed in the colon to control disease in this model (5). Rather, Treg act on responder $\mathrm{T}$ cells in the secondary lymphoid organs. In contrast, in the curative model, Treg are required to migrate to the inflamed colon to resolve ongoing inflammation. Hence, $\alpha v$ integrins are dispensable for Treg to control T cell activation either in the steady or during the initiation of inflammation in secondary lymphoid organs, but are crucial to allow Treg to accumulate specifically in the inflamed gut and resolve inflammation.

Regulatory $\mathrm{T}$ cells appear not to be a homogenous population of cells with consistent regulatory functions. So-called "central" Treg are thought to represent a Treg pool responsible to keep homeostasis and control $\mathrm{T}$ cell activation in the secondary lymphoid organs. These have been characterized by expression of CCR7 and CD62L, directing their circulation through the lymphoid tissues $(10,17)$. On the other hand, so called "effector Treg" are deemed important in controlling inflammation in peripheral tissue, and among the markers attributed to this functional subgroup are KLRG1 and CD103 (18, 50, 51). Our study shows that $\alpha \mathrm{v}$ integrins are important for the effector Treg function specifically in the context of the inflamed gut, but are redundant for the central Treg function of maintaining immune homeostasis.

\section{Active TGF- $\beta$ Leads to Downregulation of $\alpha v$ Integrins on $\mathrm{CD}^{+} \mathrm{T}$ Cells}

During iTreg generation, it was observed that $\alpha v$ surface expression was lost not only on CD4 $4^{+} \mathrm{T}$ cells from Foxp3- $\alpha \mathrm{v}^{-/-}$mice, but also on WT cells. This prompted further investigation and it was found that, in both conventional $\mathrm{T}$ cells and Treg, the presence of active TGF- $\beta$ in the culture medium resulted in reduced surface $\alpha \mathrm{v}$ levels, attributable at least in part to TGF- $\beta$ signaling. Active TGF- $\beta$ itself cannot bind to $\alpha \mathrm{v}$ integrins, as the RGD tripeptide sequence that functions as integrin $\alpha \mathrm{v}$ binding site is within the latency-associated peptide (52). It can therefore be excluded that observed reductions in $\alpha v$ levels are an artifact due to blocking of the binding site for the analysis antibody by TGF- $\beta$. It could be postulated that active TGF- $\beta$ acts as a negative feedback regulator for $\alpha \mathrm{v}$ integrin expression, since they have been implicated in the activation of latent TGF- $\beta$ by a multitude of cell types (22). However, this finding stands in contrast to reports that $\alpha \mathrm{v}$ integrins are upregulated by TGF- $\beta$ signaling in several cell types including epithelial cells (53), keratinocytes $(54)$ and fibroblasts $(55,56)$. While these divergent consequences of TGF- $\beta$ signaling with respect to $\alpha \mathrm{v}$ integrin expression deserve further investigation, they may well reflect the different biological contexts of TGF- $\beta$ signaling in these cells.

\section{av $\beta 8$ Is Redundant in Treg Function during Colitis}

Regulatory $\mathrm{T}$ cells lacking integrin $\beta 8$ showed no impaired capacity to reverse colitis. It is therefore notable that we could not confirm a reported crucial role for $\alpha v \beta 8$, acting via activation of latent TGF- $\beta$, in this context (28). While we did not assess TGF- $\beta$ activation or signaling, lack of a clinical deficiency when using $\beta 8$-deficient Treg implies that this mechanism is redundant in this setting. Considering the high redundancy within $\alpha \mathrm{v}$ integrins, with all $\alpha \mathrm{v}$ integrins binding the RGD tripeptide sequence present in ECM components and latent TGF- $\beta$, a lack of $\alpha v \beta 8$ may well be compensated by other $\alpha \mathrm{v}$ integrins. We can only speculate on reasons for the discrepancy in results, despite having used the same curative model of $\mathrm{T}$ cell transfer colitis. Our findings are consistent with previous reports in that $\alpha v \beta 8$-mediated TGF- $\beta$ activation was not required for the prevention of $\mathrm{T}$ cell induced colitis $(27,28)$. It therefore appears that the requirement of $\alpha v \beta 8$ mediated TGF- $\beta$ activation is highly context-specific, and minor differences in experimental settings or the microbiota (57) of the utilized mice may be able to explain the contrasting results. Another report further supports this notion, showing that $\alpha v \beta 8$ was not required in an oral tolerance model, despite the fact that Treg-derived TGF- $\beta$ was crucial for the induction of tolerance in that model (58).

\section{$\alpha v$ Integrins Are Not Required for Treg Migration or Disease Resolution in EAE}

A context-specific role for $\alpha \mathrm{v}$ integrins is also highlighted in our own findings, since Foxp $3-\alpha \mathrm{v}^{-1-}$ mice did not replicate the exacerbated and prolonged clinical course of EAE seen in WT mice depleted of Treg (35-37). While it is unclear whether Treg exert their function solely in the inflamed CNS or whether interactions with other immune cells are also important during the priming period in the periphery, it is evident from our 
data that $\alpha \mathrm{v}$ integrins are not required for Treg to successfully migrate to the CNS and resolve disease. However, it cannot be ruled out with certainty that compensatory mechanisms may be masking a role for Treg $\alpha \mathrm{v}$ integrins in the resolution of EAE; such mechanisms in effector T cells have previously been reported (23). It should be noted that WT Treg in the inflamed CNS exhibited high $\alpha v$ levels, as did WT Treg retrieved from the colon during a colitis model. The different functional implication of the loss of Treg $\alpha \mathrm{v}$ integrins in these two models suggests that, at least in the case of $\alpha v$, Treg change their expression pattern upon activation in a non-specific manner. This is also supported by the heightened $\alpha$ v expression levels in colonic Treg under steady state, which are known to display a more activated phenotype than their splenic counterparts (59). In effector T cells, this indeed appears to be the case, whereby $\alpha \mathrm{v}$ was shown to be upregulated upon $\mathrm{T}$ cell activation in the lymph node, rather than at the site of inflammation (23). While an individual facet of these apparently global phenotypic changes seen among activated Treg may be critical to their function in one inflammatory setting, it can be entirely superfluous in another. This may be the basis of the high variability of reports assessing the functional relevance of specific gene expression changes in Treg, such as the highly debated role of T-bet expression in Treg function $(8,9,12,60,61)$.

\section{Conclusion}

In summary, our data provide evidence for a role of $\alpha \mathrm{v}$ integrins in the successful accumulation of Treg in the inflamed colon, which is required for disease resolution. However, we did not identify $\alpha v \beta 8$ as the integrin specifically required for resolution of colitis, indicating redundancy across the $\alpha v$ integrins. The superfluous role of $\alpha \mathrm{v}$ integrins in Treg-dependent resolution of CNS inflammation highlights the necessity to unravel Treg mechanisms of action for individual diseases in order to target Treg successfully during inflammatory disease.

\section{REFERENCES}

1. Trzonkowski P, Bacchetta R, Battaglia M, Berglund D, Bohnenkamp HR, ten Brinke A, et al. Hurdles in therapy with regulatory T cells. Sci Transl Med (2015) 7(304):s18-304. doi:10.1126/scitranslmed.aaa7721

2. Brusko TM, Putnam AL, Bluestone JA. Human regulatory T cells: role in autoimmune disease and therapeutic opportunities. Immunol Rev (2008) 223(1):371-90. doi:10.1111/j.1600-065X.2008.00637.x

3. Caridade M, Graca L, Ribeiro RM. Mechanisms underlying CD4+ Treg immune regulation in the adult: from experiments to models. Front Immunol (2013) 4:378. doi:10.3389/fimmu.2013.00378

4. Vasanthakumar A, Moro K, Xin A, Liao Y, Gloury R, Kawamoto S, et al. The transcriptional regulators IRF4, BATF and IL-33 orchestrate development and maintenance of adipose tissue-resident regulatory T cells. Nat Immunol (2015) 16(3):276-85. doi:10.1038/ni.3085

5. Denning TL, Kim G, Kronenberg M. Cutting edge: CD4+CD25+ regulatory $\mathrm{T}$ cells impaired for intestinal homing can prevent colitis. J Immunol (2005) 174(12):7487-91. doi:10.4049/jimmunol.174.12.7487

6. Chaudhry A, Samstein RM, Treuting P, Liang Y, Pils MC, Heinrich J-M, et al. Interleukin-10 signaling in regulatory $\mathrm{T}$ cells is required for suppression of Th17 cell-mediated inflammation. Immunity (2011) 34(4):566-78. doi:10.1016/j.immuni.2011.03.018

\section{ETHICS STATEMENT}

This study was carried out in accordance with UK legislation. The protocol was approved by the University of Edinburgh Ethical Review Committee.

\section{AUTHOR CONTRIBUTIONS}

IM designed, performed, and analyzed experiments, interpreted the data, and wrote the article. SZ, IT, LS, RM, ML, and DS performed experiments and contributed to experimental design and methods. $\mathrm{NH}$ provided mice and helped to interpret the data. RO and SA designed experiments and assisted with data interpretation. SA contributed to writing the article. All authors revised the article.

\section{ACKNOWLEDGMENTS}

We thank Dr. A. Rudensky for provision of Foxp3 $3^{\operatorname{tm} 4(Y F P / c r e) A y r}$ mice. We thank Dr. A. Lacy-Hulbert and Dr. J. M. Proctor and for provision of $\operatorname{Itgav} v^{\mathrm{f} / \mathrm{fl}}$ mice and $\operatorname{Itg} b 8^{\mathrm{f} / \mathrm{fl}}$ mice, respectively. We thank Dr. M. J. Arends for establishing the histological colitis scoring system, and the QMRI Flow Cytometry and Cell Sorting Facility for their technical assistance.

\section{FUNDING}

This work was supported by grants from the Medical Research Council (grant numbers G1100084 and MR/M00242X/1) and the Wellcome Trust (grant number 103749).

\section{SUPPLEMENTARY MATERIAL}

The Supplementary Material for this article can be found online at http://www.frontiersin.org/articles/10.3389/fimmu.2018.00264/ full\#supplementary-material.

7. Yamazaki T, Yang XO, Chung Y, Fukunaga A, Nurieva R, Pappu B, et al. CCR6 regulates the migration of inflammatory and regulatory $\mathrm{T}$ cells. J Immunol (2008) 181(12):8391-401. doi:10.4049/jimmunol.181.12.8391

8. Xiong Y, Ahmad S, Iwami D, Colin C, Bromberg JS. T-bet regulates natural regulatory $\mathrm{T}$ Cell afferent lymphatic migration and suppressive function. J Immunol (2016) 196(6):2526-40. doi:10.4049/jimmunol.1502537

9. McPherson RC, Turner DG, Mair I, O'Connor RA, Anderton SM. T-bet expression by Foxp3(+) T regulatory cells is not essential for their suppressive function in CNS autoimmune disease or colitis. Front Immunol (2015) 6:69. doi:10.3389/fimmu.2015.00069

10. Smigiel KS, Richards E, Srivastava S, Thomas KR, Dudda JC, Klonowski KD, et al. CCR7 provides localized access to IL-2 and defines homeostatically distinct regulatory T cell subsets. J Exp Med (2014) 211(1):121-36. doi:10.1084/ jem.20131142

11. Tadokoro CE, Shakhar G, Shen S, Ding Y, Lino AC, Maraver A, et al. Regulatory T cells inhibit stable contacts between CD4+ T cells and dendritic cells in vivo. J Exp Med (2006) 203(3):505-11. doi:10.1084/jem.20050783

12. Colbeck EJ, Hindley JP, Smart K, Jones E, Bloom A, Bridgeman H, et al. Eliminating roles for T-bet and IL-2 but revealing superior activation and proliferation as mechanisms underpinning dominance of regulatory $\mathrm{T}$ cells in tumors. Oncotarget (2015) 6(28):24649-59. doi:10.18632/ oncotarget.5584 
13. Gratz IK, Truong H-A, Yang SH-Y, Maurano MM, Lee K, Abbas AK, et al. Cutting Edge: memory regulatory t cells require IL-7 and not IL-2 for their maintenance in peripheral tissues. J Immunol (2013) 190(9):4483-7. doi:10.4049/ jimmunol.1300212

14. Sather BD, Treuting P, Perdue N, Miazgowicz M, Fontenot JD, Rudensky AY, et al. Altering the distribution of Foxp3+ regulatory $\mathrm{T}$ cells results in tissuespecific inflammatory disease. J Exp Med (2007) 204(6):1335-47. doi:10.1084/ jem. 20070081

15. Kitamura K, Farber JM, Kelsall BL. CCR6 marks regulatory T cells as a colontropic, IL-10-producing phenotype. J Immunol (2010) 185(6):3295-304. doi:10.4049/jimmunol.1001156

16. Lee J-W, Epardaud M, Sun J, Becker JE, Cheng AC, Yonekura A, et al. Peripheral antigen display by lymph node stroma promotes $\mathrm{T}$ cell tolerance to intestinal self. Nat Immunol (2007) 8(2):181-90. doi:10.1038/ni1427

17. Huehn J, Siegmund K, Lehmann JC, Siewert C, Haubold U, Feuerer M, et al. Developmental stage, phenotype, and migration distinguish naive- and effector/memory-like CD4+ regulatory T cells. J Exp Med (2004) 199(3):303-13. doi:10.1084/jem.20031562

18. Suffia I, Reckling SK, Salay G, Belkaid Y. A role for CD103 in the retention of CD4+CD25+ Treg and control of Leishmania major infection. J Immunol (2005) 174(9):5444-55. doi:10.4049/jimmunol.174.9.5444

19. Glatigny S, Duhen R, Arbelaez C, Kumari S, Bettelli E. Integrin alpha L controls the homing of regulatory $\mathrm{T}$ cells during CNS autoimmunity in the absence of integrin alpha 4. Sci Rep (2015) 5:7834. doi:10.1038/srep07834

20. Xiong J, Balcioglu HE, Danen EHJ. Integrin signaling in control of tumor growth and progression. Int J Biochem Cell Biol (2013) 45(5):1012-5. doi:10.1016/j.biocel.2013.02.005

21. van der Flier A, Sonnenberg A. Function and interactions of integrins. Cell Tissue Res (2001) 305(3):285-98. doi:10.1007/s004410100417

22. Wipff PJ, Hinz B. Integrins and the activation of latent transforming growth factor $\beta 1$ - An intimate relationship. Eur J Cell Biol (2008) 87(8-9):601-15. doi:10.1016/j.ejcb.2008.01.012

23. Overstreet MG, Gaylo A, Angermann BR, Hughson A, Hyun Y-M, Lambert K, et al. Inflammation-induced interstitial migration of effector $\mathrm{CD} 4^{+} \mathrm{T}$ cells is dependent on integrin $\alpha$ V. Nat Immunol (2013) 14(9):949-58. doi:10.1038/ni.2682

24. Travis MA, Reizis B, Melton AC, Masteller E, Tang Q, Proctor JM, et al. Loss of integrin alpha $(\alpha)$ beta8 on dendritic cells causes autoimmunity and colitis in mice. Nature (2007) 449(7160):361-5. doi:10.1038/nature06110

25. Lacy-Hulbert A, Smith AM, Tissire H, Barry M, Crowley D, Bronson RT, et al. Ulcerative colitis and autoimmunity induced by loss of myeloid $\mathrm{v}$ integrins. Proc Natl Acad Sci U S A (2007) 104(40):15823-8. doi:10.1073/pnas. 0707421104

26. Païdassi H, Acharya M, Zhang A, Mukhopadhyay S, Kwon M, Chow C, et al. Preferential expression of integrin $\alpha v \beta 8$ promotes generation of regulatory T cells by mouse CD103 + dendritic cells. Gastroenterology (2011) 141(5):1813-20. doi:10.1053/j.gastro.2011.06.076

27. Edwards JP, Thornton AM, Shevach EM. Release of active TGF- $\beta 1$ from the latent TGF- $\beta 1 /$ GARP complex on T regulatory cells is mediated by integrin B8. J Immunol (2014) 193(6):2843-9. doi:10.4049/jimmunol.1401102

28. Worthington JJ, Kelly A, Smedley C, Bauche D, Campbell S, Marie JC, et al. Integrin $\alpha v \beta 8$-mediated TGF- $\beta$ activation by effector regulatory $\mathrm{T}$ cells is essential for suppression of T-cell-mediated inflammation. Immunity (2015) 42(5):903-15. doi:10.1016/j.immuni.2015.04.012

29. Barnden MJ, Allison J, Heath WR, Carbone FR. Defective TCR expression in transgenic mice constructed using cDNA-based alpha- and beta-chain genes under the control of heterologous regulatory elements. Immunol Cell Biol (1998) 76(1):34-40. doi:10.1046/j.1440-1711.1998.00709.x

30. Rubtsov YP, Rasmussen JP, Chi EY, Fontenot J, Castelli L, YeX, et al. Regulatory $\mathrm{T}$ cell-derived interleukin-10 limits inflammation at environmental interfaces. Immunity (2008) 28(4):546-58. doi:10.1016/j.immuni.2008.02.017

31. Proctor JM, Zang K, Wang D, Wang R, Reichardt LF. Vascular development of the brain requires beta8 integrin expression in the neuroepithelium. J Neurosci (2005) 25(43):9940-8. doi:10.1523/JNEUROSCI.3467-05.2005

32. O'Connor RA, Leech MD, Suffner J, Hammerling GJ, Anderton SM. Myelinreactive, TGF- -induced regulatory $\mathrm{T}$ cells can be programmed to develop Th1-like effector function but remain less proinflammatory than myelinreactive Th1 effectors and can suppress pathogenic $\mathrm{T}$ cell clonal expansion in vivo. J Immunol (2010) 185(12):7235-43. doi:10.4049/jimmunol.1001551
33. Leech MD, Barr TA, Turner DG, Brown S, O'Connor RA, Gray D, et al. Cutting edge: IL-6-dependent autoimmune disease: dendritic cells as a sufficient, but transient, source. J Immunol (2013) 190(3):881-5. doi:10.4049/jimmunol. 1202925

34. O'Connor R, Malpass KH, Anderton SM. The inflamed central nervous system drives the activation and rapid proliferation of Foxp3+ regulatory $\mathrm{T}$ cells. J Immunol (2007) 179(2):958-66. doi:10.4049/jimmunol.179.2.958

35. McGeachy MJ, Stephens LA, Anderton SM. Natural recovery and protection from autoimmune encephalomyelitis: contribution of $\mathrm{CD} 4+\mathrm{CD} 25+$ regulatory cells within the central nervous system. J Immunol (2005) 175:3025-32. doi:10.4049/jimmunol.175.5.3025

36. Zhang X, Koldzic D, Izikson L, Reddy J, Nazareno R, Sakaguchi S, et al. IL-10 is involved in the suppression of experimental autoimmune encephalomyelitis by CD25+CD4+ regulatory T cells. Int Immunol (2004) 16(2):249-56. doi:10.1093/intimm/dxh029

37. Gärtner D, Hoff H, Gimsa U, Burmester G-R, Brunner-Weinzierl MC. CD25 regulatory $\mathrm{T}$ cells determine secondary but not primary remission in EAE: impact on long-term disease progression. J Neuroimmunol (2006) 172(1-2):73-84. doi:10.1016/j.jneuroim.2005.11.003

38. Mottet C, Uhlig HH, Powrie F. Cutting edge: cure of colitis by CD4+CD25+ regulatory T cells. J Immunol (2003) 170(8):3939-43. doi:10.4049/jimmunol. 170.8.3939

39. Haribhai D, Lin W, Edwards B, Ziegelbauer J, Salzman NH, Carlson MR, et al. A central role for induced regulatory $\mathrm{T}$ cells in tolerance induction in experimental colitis. JImmunol (2009) 182(6):3461-8. doi:10.4049/ jimmunol.0802535

40. Ridley AJ, Schwartz MA, Burridge K, Firtel RA, Ginsberg MH, Borisy G, et al. Cell migration: integrating signals from front to back. Science (2003) 302(5651):1704-9. doi:10.1126/science.1092053

41. Feuerer M, Herrero L, Cipolletta D, Naaz A, Wong J, Nayer A, et al. Lean, but not obese, fat is enriched for a unique population of regulatory $\mathrm{T}$ cells that affect metabolic parameters. Nat Med (2009) 15(8):930-9. doi:10.1038/ nm.2002

42. Burzyn D, Kuswanto W, Kolodin D, Shadrach JL, Cerletti M, Jang Y, et al. A special population of regulatory $\mathrm{T}$ cells potentiates muscle repair. Cell (2013) 155(6):1282-95. doi:10.1016/j.cell.2013.10.054

43. Hill JA, Feuerer M, Tash K, Haxhinasto S, Perez J, Melamed R, et al. Foxp3 transcription-factor-dependent and -independent regulation of the regulatory T cell transcriptional signature. Immunity (2007) 27(5):786-800. doi:10.1016/j. immuni.2007.09.010

44. Burzyn D, Benoist C, Mathis D. Regulatory T cells in nonlymphoid tissues. Nat Immunol (2013) 14(10):1007-13. doi:10.1038/ni.2683

45. Schiering C, Krausgruber T, Chomka A, Fröhlich A, Adelmann K, WohlfertEA, et al. The alarmin IL-33 promotes regulatory T-cell function in the intestine. Nature (2014) 513(7519):564-8. doi:10.1038/nature13577

46. Setoguchi R, Hori S, Takahashi T, Sakaguchi S. Homeostatic maintenance of natural Foxp3(+) CD25(+) CD4(+) regulatory T cells by interleukin (IL)-2 and induction of autoimmune disease by IL-2 neutralization. J Exp Med (2005) 201(5):723-35. doi:10.1084/jem.20041982

47. Pierson W, Cauwe B, Policheni A, Schlenner SM, Franckaert D, Berges J, et al. Antiapoptotic Mcl-1 is critical for the survival and niche-filling capacity of Foxp3 $3^{+}$regulatory T cells. Nat Immunol (2013) 14(9):959-65. doi:10.1038/ ni. 2649

48. Uhlig HH, Coombes J, Mottet C, Izcue A, Thompson C, Fanger A, et al. Characterization of Foxp3+CD4+CD25+ and IL-10-secreting CD4+CD25+ T cells during cure of colitis. J Immunol (2006) 177(9):5852-60. doi:10.4049/ jimmunol.177.9.5852

49. Bader BL, Rayburn H, Crowley D, Hynes RO. Extensive vasculogenesis, angiogenesis, and organogenesis precede lethality in mice lacking all alpha v integrins. Cell (1998) 95(4):507-19. doi:10.1016/S0092-8674(00)81618-9

50. Feuerer M, Hill JA, Kretschmer K, von Boehmer H, Mathis D, Benoist C. Genomic definition of multiple ex vivo regulatory T cell subphenotypes. Proc Natl Acad Sci U S A (2010) 107(13):5919-24. doi:10.1073/pnas.1002006107

51. Beyersdorf N, Ding X, Tietze JK, Hanke T. Characterization of mouse CD4 T cell subsets defined by expression of KLRG1. Eur J Immunol (2007) 37(12):3445-54. doi:10.1002/eji.200737126

52. Munger JS, Harpel JG, Giancotti FG, Rifkin DB. Interactions between growth factors and integrins: latent forms of transforming growth factor-beta are 
ligands for the integrin alphavbeta1. Mol Biol Cell (1998) 9(9):2627-38. doi:10.1091/mbc.9.9.2627

53. Sheppard D, Cohen DS, Wang A, Busk M. Transforming growth factor beta differentially regulates expression of integrin subunits in guinea pig airway epithelial cells. J Biol Chem (1992) 267(24):17409-14.

54. Zambruno G, Marchisio PC, Marconi A, Vaschieri C, Melchiori A, Giannetti A, et al. Transforming growth factor-beta 1 modulates beta 1 and beta 5 integrin receptors and induces the de novo expression of the alpha $\mathrm{v}$ beta 6 heterodimer in normal human keratinocytes: implications for wound healing. J Cell Biol (1995) 129(3):853-65. doi:10.1083/jcb.129.3.853

55. Graf K, Neuss M, Stawowy P, Hsueh WA, Fleck E, Law RE. Angiotensin II and alpha $(\alpha)$ beta $(\beta)$ integrin expression in rat neonatal cardiac fibroblasts. Hypertension (2000) 35(4):978-84. doi:10.1161/01.HYP.35.4.978

56. Scaffidi AK, Petrovic N, Moodley YP, Fogel-Petrovic M, Kroeger KM, Seeber RM, et al. alpha $(\alpha)$ beta $(\beta)$ Integrin interacts with the transforming growth factor beta (TGFbeta) type II receptor to potentiate the proliferative effects of TGFbetal in living human lung fibroblasts. J Biol Chem (2004) 279(36):37726-33. doi:10.1074/jbc.M403010200

57. Kamada N, Núñez G. Role of the gut microbiota in the development and function of lymphoid cells. J Immunol (2013) 190(4):1389-95. doi:10.4049/ jimmunol.1203100

58. Edwards JP, Hand TW, Morais da Fonseca D, Glass DD, Belkaid Y, Shevach EM. The GARP/latent TGF- $\beta 1$ complex on Treg cells modulates the induction of peripherally derived Treg cells during oral tolerance. Eur J Immunol (2016) 46(6):1480-9. doi:10.1002/eji.201546204
59. Levine AG, Jin W, Rudensky AY, Arvey A, et al. Continuous requirement for the TCR in regulatory T cell function. Nat Immunol (2014) 15(11):1070-8. doi:10.1038/ni.3004

60. Koch MA, Tucker-Heard G, Perdue NR, Killebrew JR, Urdahl KB, Campbell DJ. The transcription factor T-bet controls regulatory $\mathrm{T}$ cell homeostasis and function during type 1 inflammation. Nat Immunol (2009) 10(6):595-602. doi:10.1038/ni.1731

61. Koch MA, Thomas KR, Perdue NR, Smigiel KS, Srivastava S, Campbell DJ. T-bet(+) Treg cells undergo abortive Th1 cell differentiation due to impaired expression of IL-12 receptor $\beta 2$. Immunity (2012) 37(3):501-10. doi:10.1016/j. immuni.2012.05.031

Conflict of Interest Statement: The authors declare that the research was conducted in the absence of any commercial or financial relationships that could be construed as a potential conflict of interest.

The reviewer CS and handling editor declared their shared affiliation.

Copyright (® 2018 Mair, Zandee, Toor, Saul, McPherson, Leech, Smyth, O'Connor, Henderson and Anderton. This is an open-access article distributed under the terms of the Creative Commons Attribution License (CC BY). The use, distribution or reproduction in other forums is permitted, provided the original author(s) and the copyright owner are credited and that the original publication in this journal is cited, in accordance with accepted academic practice. No use, distribution or reproduction is permitted which does not comply with these terms. 